\title{
Rescue Angioplasty after Failed Thrombolytic Therapy for Acute Myocardial Infarction
}

\author{
Anthony H. Gershlick, M.B., B.S., Amanda Stephens-Lloyd, R.N., M.Sc., \\ Sarah Hughes, R.N., B.A., Keith R. Abrams, Ph.D., Suzanne E. Stevens, M.Sc., \\ Neal G. Uren, M.D., Adam de Belder, M.D., John Davis, M.B., B.S., \\ Michael Pitt, M.B., B.S., Adrian Banning, M.D., Andreas Baumbach, M.D., \\ Man Fai Shiu, M.D., Peter Schofield, M.D., Keith D. Dawkins, M.D., \\ Robert A. Henderson, M.D., Keith G. Oldroyd, M.D., and Robert Wilcox, M.D., \\ for the REACT Trial Investigators*
}

ABSTRACT

From the Department of Cardiology, University Hospitals of Leicester, Leiceste (A.H.G., A.S.-L., S.H.); the Departments of Health Sciences (K.R.A.) and Cardiovascular Sciences (S.E.S.), University of Leicester, Leicester; the Department of Cardiology, Royal Infirmary Edinburgh, Edinburgh (N.G.U.); Sussex Cardiac Cen tre, Royal Sussex County Hospital, Brighton (A. de Belder); the Department of Cardiology, North Staffordshire Hospital, Stoke-on-Trent (J.D.); the Department of Cardiology, Heartlands Hospital Birmingham (M.P.); the Department of Cardiology, John Radcliffe Hospital, Ox ford (A. Banning); the Department of Cardiology, Bristol Royal Infirmary, Bris tol (A. Baumbach); the Department of Cardiology, Walsgrave Hospital, Coventry (M.F.S.); the Department of Cardiolo gy, Papworth Hospital, Cambridge (P.S.); Wessex Cardiac Unit, Southampton Gen eral Hospital, Southampton (K.D.D.) Trent Cardiac Centre, Nottingham City Hospital, Nottingham (R.A.H.); the De partment of Cardiology, Western Infirmary, Glasgow (K.G.O.); and the Department of Cardiovascular Medicine, Queens Medical Centre, Nottingham (R.W.) - all in the United Kingdom. Ad dress reprint requests to Dr. Gershlick at the University Hospitals of Leicester, Groby St., Leicester LE3 9QP, United Kingdom, or at agershlick@aol.com.

*The participants in the Rescue Angioplasty versus Conservative Treatment or Repeat Thrombolysis (REACT) trial are listed in the Appendix.

N EnglJ Med 2005;353:2758-68. Copyright (c) 2005 Massachusetts Medical Society.

\section{BACKGROUND}

The appropriate treatment for patients in whom reperfusion fails to occur after thrombolytic therapy for acute myocardial infarction remains unclear. There are few data comparing emergency percutaneous coronary intervention (rescue PCI) with conservative care in such patients, and none comparing rescue PCI with repeated thrombolysis.

METHODS

We conducted a multicenter trial in the United Kingdom involving 427 patients with ST-segment elevation myocardial infarction in whom reperfusion failed to occur (less than 50 percent ST-segment resolution) within 90 minutes after thrombolytic treatment. The patients were randomly assigned to repeated thrombolysis (142 patients), conservative treatment (141 patients), or rescue PCI (144 patients). The primary end point was a composite of death, reinfarction, stroke, or severe heart failure within six months.

RESULTS

The rate of event-free survival among patients treated with rescue PCI was 84.6 percent, as compared with 70.1 percent among those receiving conservative therapy and 68.7 percent among those undergoing repeated thrombolysis (overall $\mathrm{P}=0.004$ ). The adjusted hazard ratio for the occurrence of the primary end point for repeated thrombolysis versus conservative therapy was 1.09 (95 percent confidence interval, 0.71 to $1.67 ; \mathrm{P}=0.69$ ), as compared with adjusted hazard ratios of 0.43 (95 percent confidence interval, 0.26 to $0.72 ; \mathrm{P}=0.001$ ) for rescue PCI versus repeated thrombolysis and 0.47 ( 95 percent confidence interval, 0.28 to $0.79 ; \mathrm{P}=0.004$ ) for rescue PCI versus conservative therapy. There were no significant differences in mortality from all causes. Nonfatal bleeding, mostly at the sheath-insertion site, was more common with rescue PCI. At six months, 86.2 percent of the rescue-PCI group were free from revascularization, as compared with 77.6 percent of the conservative-therapy group and 74.4 percent of the repeated-thrombolysis group (overall $\mathrm{P}=0.05$ ).

\section{CONCLUSIONS}

Event-free survival after failed thrombolytic therapy was significantly higher with rescue PCI than with repeated thrombolysis or conservative treatment. Rescue PCI should be considered for patients in whom reperfusion fails to occur after thrombolytic therapy. 
P

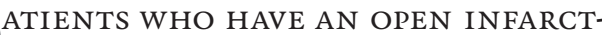
related artery after acute myocardial infarction with ST-segment elevation have better clinical outcomes than patients without an open artery. ${ }^{1-4}$ Although primary percutaneous coronary intervention (primary PCI) is a proven therapeutic approach in this setting ${ }^{5,6}$ and is used increasingly, intravenous thrombolysis remains the first-line therapy in 30 to 70 percent of cases worldwide..$^{7,8}$ However, thrombolysis results in a grade 3 flow, according to the Thrombolysis in Myocardial Infarction (TIMI) classification system, in only 60 percent of patients, even with current fibrin-specific agents. ${ }^{9}$ To date, it has been unclear how best to treat the remaining patients, in whom thrombolysis has failed. Some physicians, particularly those at hospitals without interventional facilities, treat such patients conservatively. ${ }^{10}$ Others believe that a second dose of a thrombolytic agent may be beneficial. ${ }^{11}$ Many advocate emergency PCI (rescue PCI) on the basis of small trials that have suggested a benefit of this intervention. ${ }^{12,13}$ The Rescue Angioplasty versus Conservative Treatment or Repeat Thrombolysis (REACT) trial was undertaken to establish which of these three options achieves the best clinical outcome among patients in whom thrombolysis has failed.

\section{METHODS}

We conducted a multicenter, randomized, parallel-group trial that was approved by United Kingdom national and local ethics committees and fulfilled the conditions of the Declaration of Helsinki. The trial was funded by the British Heart Foundation; Roche Pharmaceuticals provided reteplase for repeated thrombolysis (its use was optional for physician investigators). The sponsors had no role in study design, data collection, or study analysis or in the writing of this report.

\section{PATIENTS}

Between December 1999 and March 2004, trial candidates were evaluated at 35 centers (which joined the study on a rolling basis over three years); 19 of the centers had on-site angiographic facilities. Adults 21 to 85 years of age were eligible for inclusion if they had received any licensed thrombolytic agent for myocardial infarction with STsegment elevation within 6 hours of the onset of chest pain and if reperfusion had then failed to occur, as judged by the predetermined 90 -minute electrocardiographic criterion (less than 50 percent resolution in the lead with previous maximal ST-segment elevation). The inclusion and exclusion criteria are listed in Table 1. A screening log of potential subjects was kept through November 2002 to catalogue patients who did or did not participate in the trial; however, this log was not maintained after November 2002 because of funding constraints. The trial subjects were enrolled after giving written informed consent.

\section{RANDOMIZATION}

Patients were randomly assigned by a 24-hour computer-generated random-allocation system to undergo repeated thrombolysis, conservative treatment, or rescue PCI. Patients assigned to repeated thrombolysis received a fibrin-specific thrombolytic agent (alteplase or reteplase, according to the physician's choice) and intravenous heparin, according to standard clinical practice. Low-molecular-weight heparin was not used in the first 24 hours. Patients assigned to the conservative-therapy group received standard medical therapy for myocardial infarction without thrombolysis or PCI. To ensure a standardized group, conservative therapy included intravenous heparin for 24 hours, irrespective of the first thrombolytic agent. Heparin administration in the repeated-thrombolysis and conservative-therapy groups was titrated to an activated partial-thromboplastin time ratio of 1.5 to 2.5. Patients assigned to rescue PCI underwent coronary angiography, proceeding to angioplasty if required (i.e., if the patient had less than TIMI grade 3 flow and more than 50 percent stenosis in the infarct-related artery). Adjunctive strategies (e.g., stenting or glycoprotein IIb/IIIa receptor inhibition) were used at the discretion of the interventionist. Crossover among the three treatment groups was discouraged but was allowed if a patient had ongoing or further chest pain associated with ST-segment re-elevation or new elevation in at least two contiguous leads or had cardiogenic shock.

\section{DATA COLLECTION}

Clinical examination, electrocardiography, hematologic measurements, and biochemical tests (including measurement of cardiac biomarkers) were performed on all patients 4 hours after the initiation of the randomly assigned therapy (to account for the potential time delay to rescue PCI), at 12 and 24 hours after randomization, and at dis- 
Table 1. Criteria for Inclusion and Exclusion and Definitions of Trial End Points.

\section{Inclusion criteria}

Acute myocardial infarction with ST-segment elevation of more than $0.1 \mathrm{mV}$ in at least two contiguous leads, excluding $\mathrm{V}_{1}$

Aspirin and thrombolysis administered within 6 hours of onset of symptoms

Age 21 to 85 years

Ability to give informed consent

At 90 minutes ( \pm 15 minutes) after the beginning of initial thrombolytic therapy, electrocardiogram shows failed thrombolytic therapy - i.e., less than $50 \%$ resolution of the ST segment in the lead showing the greatest ST-segment elevation measured from the baseline (isoelectric line) to $80 \mathrm{msec}$ beyond the J point, with or without chest pain

Rescue angioplasty, if assigned, can be performed within 12 hours of the onset of pain

\section{Exclusion criteria}

Probable inability to gain femoral access for intervention (e.g., severe peripheral vascular disease)

Left bundle-branch block

Life expectancy less than 6 months owing to noncardiac cause

Previous inclusion in this trial at any time, or in any other clinical trial during the previous month

Contraindication to thrombolysis (e.g., cardiopulmonary resuscitation after first thrombolytic treatment)

Hemoglobin greater than $1.5 \mathrm{~g} / \mathrm{dl}$ below normal range within previous 6 hours

Platelet count below normal range within previous 6 hours

For patients 75 years of age or older: systolic blood pressure above $200 \mathrm{~mm} \mathrm{Hg}$, diastolic blood pressure above $100 \mathrm{~mm} \mathrm{Hg}$, or both at any time during the current episode of pain, even if successfully reduced by therapy

For patients less than 75 years of age: after prescription of first thrombolytic therapy, systolic blood pressure above $200 \mathrm{~mm} \mathrm{Hg}$, diastolic blood pressure above $100 \mathrm{~mm} \mathrm{Hg}$, or both on more than one occasion

Estimated body weight less than $65 \mathrm{~kg}$

Cardiogenic shock, either in the opinion of the investigator or defined as persistent (lasting more than 30 minutes) systolic hypotension (less than $90 \mathrm{~mm} \mathrm{Hg}$ ) with oliguria and autonomic activation, with or without pulmonary edema despite appropriate volume replacement, and considered to be due to ventricular dysfunction rather than to any other cause

Administration of low-molecular-weight heparin within the previous 12 hours

\section{Definitions of trial end points}

Reinfarction

During index admission: further chest pain lasting more than 30 minutes and accompanied by new electrocardiographic changes (new $\mathrm{Q}$ waves above 0.04 second or ST-segment elevation above $0.1 \mathrm{mV}$ in two leads for more than 30 minutes), further enzyme rise, or both

Late chest pain lasting more than 30 minutes and accompanied by new electrocardiographic changes, enzyme rise, or both

Cerebrovascular event

A new focal neurologic deficit of presumed vascular cause persisting for more than 24 hours and without evidence of a nonvascular cause according to a neurologic imaging study

Severe heart failure

Early heart failure: any new-onset cardiogenic shock or heart failure with pulmonary edema that is resistant to medical therapy and that occurs during the index admission and after randomization

Late heart failure: admission to hospital for treatment of heart failure (New York Heart Association class III or IV)

Bleeding

Major bleeding: decrease in hemoglobin of at least $5 \mathrm{~g} / \mathrm{dl}$ during index admission, severe bleeding event (e.g., intracranial hemorrhage, hemopericardium, or hemodynamic compromise, with or without transfusion), or both

Minor bleeding: observed bleeding during index admission, with or without a decrease in hemoglobin of at least $5 \mathrm{~g} / \mathrm{dl}$, with or without transfusion

Blood loss with no identified site: a decrease in hemoglobin of 2 to $4.9 \mathrm{~g} / \mathrm{dl}$, or the need for transfusion, without an identified bleeding site 
charge, with clinical follow-up at 1,6 , and 12 months. The components of the primary end point were continuously documented. More than 90 percent of study data were subjected to source validation according to strictly controlled criteria.

\section{END POINTS}

The primary end point was a composite of major adverse cardiac and cerebrovascular events at six months, including death, recurrent myocardial infarction, cerebrovascular event, and severe heart failure. The secondary end points included the components of the primary end point, as well as bleeding and revascularization. Events were adjudicated by an independent end-point committee, whose members were blinded to treatment assignment. Quality-of-life and resource-use data were collected at follow-up. Definitions of all end points are given in Table 1.

\section{POWER AND SAM PLE SIZE}

On the basis of the limited evidence available at the time of study design (1998), ${ }^{12}$ the steering committee estimated that the rate of the primary composite end point in the conservative-therapy group would approach 20 percent and hypothesized a 40 percent relative reduction in this rate in the rescue-PCI group; thus, it was calculated that 1200 patients would be required (80 percent power, $\alpha=0.05$ ). In December 2001, the members of the steering committee and the data and safety monitoring committee (who did not have access to the trial data) examined new published evidence suggesting that the rate of death or recurrent myocardial infarction would be 29 percent with conservative therapy, 26.5 percent with repeated thrombolysis, and 15 percent with rescue PCI. ${ }^{11,13-15}$ Because the rates of heart failure and cerebrovascular events were inconsistently reported in those studies, the power of our study was recalculated on the basis of assumed rates of death and recurrent myocardial infarction alone. It was determined that a sample size of 156 patients in each group would provide 80 percent power $(\alpha=0.05)$ to detect the same 40 percent relative reduction in the composite end point that was previously hypothesized. It was assumed that heart failure and cerebrovascular events would be likely to increase rather than reduce such power in the final analysis.

During 2003 and 2004, enrollment in the trial began to decline. The precise reason for this decline is uncertain, because the screening log was not maintained after November 2002 (as noted above). However, other ongoing clinical trials, as well as the introduction of the new thrombolytic agent tenecteplase (and the concomitant unlicensed use of low-molecular-weight heparin), limited the number of suitable candidates for participation. Because of declining trial recruitment and a finite funding period, the steering committee terminated enrollment in the trial in March 2004.

\section{STATISTICAL ANALYSIS}

All analyses were performed on an intention-totreat basis. Process times are reported as medians with interquartile ranges and compared with use of the Kruskal-Wallis test. The proportions of subjects in each of the groups who reached any end point during the six months were compared with use of either the chi-square test or Fisher's exact test, as appropriate. Survival and event-free survival were plotted as Kaplan-Meier curves, and the log-rank test was used to compare them. Hazard ratios with 95 percent confidence intervals were calculated for all pairwise comparisons. Cox proportional-hazards regression models were used to investigate the potential influence of all baseline covariates on treatment effects. Covariates were selected for a final model by a forward variable-selection procedure. The assumption of proportional hazards was assessed both graphically, with the use of log-log survivor plots, and by adding associated time-dependent covariates to the model. ${ }^{16}$ There was no evidence that the assumption of proportional hazards was violated in any of the results presented here. No formal adjustment for multiple testing was undertaken, but the P values were interpreted cautiously. All statistical analyses were performed with SAS software, version 8.2 (SAS Institute).

\section{RESULTS}

At the termination of the trial, 435 patients had been enrolled and randomly assigned to one of the three treatment groups. Of these, six withdrew consent (one each in the groups assigned to repeated thrombolysis and rescue PCI and four in the group assigned to conservative therapy), and another two were excluded (one each in the repeated-thrombolysis and rescue-PCI groups) because they had inappropriately undergone random- 
ization before giving consent, which they declined to do. The data for 427 patients are therefore presented. Of these, 142 were assigned to repeated thrombolysis, 141 to conservative therapy, and 144 to rescue PCI (Table 2).

The trial screening log, which was maintained until November 2002, included 713 patients who did not undergo randomization (as compared with 304 patients who had undergone randomization by that date). Of those who did not undergo randomization, most were excluded on the basis of clinical criteria, including delayed presentation (beyond six hours) (24 percent), advanced age (21.4 percent), and severe hypertension (13.6 percent). Only 4.2 percent were excluded on the basis of the judgment of the patient's physician.

\section{BASELINE CHARACTERISTICS}

The baseline characteristics were similar in all groups (Table 2). There was no difference among the groups in the median time from the onset of pain to the first (nontrial) thrombolytic treatment $(\mathrm{P}=0.73)$. The median time from presentation until the first thrombolytic treatment ("door-toneedle time") was 27 minutes (interquartile range, 16 to 43$)$.

\begin{tabular}{|c|c|c|c|c|}
\hline \multirow[t]{2}{*}{ Characteristic } & \multicolumn{3}{|c|}{ Treatment Group } & \multirow[t]{2}{*}{$\begin{array}{l}\text { All Patients } \\
\text { ( } \mathrm{N}=427)\end{array}$} \\
\hline & $\begin{array}{l}\text { Repeated } \\
\text { Thrombolysis } \\
(\mathrm{N}=142)\end{array}$ & $\begin{array}{c}\text { Conservative } \\
\text { Therapy } \\
(\mathrm{N}=141)\end{array}$ & $\begin{array}{l}\text { Rescue } \mathrm{PCl} \\
(\mathrm{N}=144)\end{array}$ & \\
\hline \multicolumn{5}{|l|}{ Age $-y r$} \\
\hline Mean \pm SD & $61.3 \pm 10.3$ & $61.0 \pm 10.7$ & $61.1 \pm 11.9$ & $61.1 \pm 11.0$ \\
\hline Range & $40-85$ & $37-85$ & $34-85$ & $34-85$ \\
\hline Male sex — no. (\%) & $114(80.3)$ & $111(78.7)$ & $113(78.5)$ & $338(79.2)$ \\
\hline \multicolumn{5}{|l|}{ Medical history — no. (\%) } \\
\hline Angina & $32(22.5)$ & $29(20.6)$ & $32(22.2)$ & $93(21.8)$ \\
\hline Acute myocardial infarction & $23(16.2)$ & $17(12.1)$ & $14(9.8) *$ & $54(12.7) *$ \\
\hline $\begin{array}{l}\text { Percutaneous coronary inter- } \\
\text { vention }\end{array}$ & $6(4.2)$ & $4(2.8)$ & $6(4.2)$ & $16(3.7)$ \\
\hline Coronary-artery bypass grafting & $7(4.9)$ & $4(2.8)$ & $7(4.9)$ & $18(4.2)$ \\
\hline Diabetes & $23(16.2)$ & $16(11.3)$ & $21(14.6)$ & $60(14.1)$ \\
\hline Hypertension & $60(42.3)$ & $53(37.6)$ & $47(32.6)$ & $160(37.5)$ \\
\hline \multicolumn{5}{|l|}{ Smoking history — no. (\%) } \\
\hline Currently smoking & $70(49.6) *$ & $65(46.1)$ & $68(47.2)$ & $203(47.7) *$ \\
\hline Formerly smoked & $41(29.1) *$ & $42(29.8)$ & $40(27.8)$ & $123(28.9) *$ \\
\hline Never smoked & $30(21.3) *$ & $34(24.1)$ & $36(25.0)$ & $100(23.5) *$ \\
\hline Anterior infarct — no. (\%) & $54(38.0)$ & $66(46.8)$ & $61(42.7) *$ & $181(42.5) *$ \\
\hline \multicolumn{5}{|l|}{$\begin{array}{l}\text { First thrombolytic therapy - } \\
\text { no. (\%) }\end{array}$} \\
\hline Reteplase & $43(30.3)$ & 28 (19.9) & $42(29.2)$ & $113(26.5)$ \\
\hline Streptokinase & $82(57.7)$ & $88(62.4)$ & $84(58.3)$ & $254(59.5)$ \\
\hline Tenecteplase & $2(1.4)$ & $5(3.5)$ & $3(2.1)$ & $10(2.3)$ \\
\hline Tissue plasminogen activator & $15(10.6)$ & $20(14.2)$ & $15(10.4)$ & $50(11.7)$ \\
\hline \multicolumn{5}{|l|}{$\begin{array}{l}\text { Time to first thrombolytic } \\
\text { therapy (min) }\end{array}$} \\
\hline Median & 135 & 150 & 140 & 140 \\
\hline Interquartile range & $94-217$ & $100-210$ & $95-240$ & $95-220$ \\
\hline
\end{tabular}

* Data were missing for one patient. 


\section{ACTUAL TREATMENT RECEIVED}

Eighteen patients (4.2 percent) did not receive their randomly assigned treatment. Among the patients who were assigned to rescue PCI, 14 received conservative therapy and 2 received repeated thrombolysis; among the patients who were assigned to repeated thrombolysis, 1 received conservative therapy and 1 received rescue PCI. The results of the analysis according to the intention-to-treat principle were unchanged when the data were analyzed according to actual treatment received.

\section{RESCUE PCI}

Of the 144 patients assigned to rescue PCI, 88 (61.1 percent) were recruited from hospitals with interventional capabilities. The median transfer time for patients from hospitals without interventional capabilities was 85 minutes (interquartile range, 55 to 120). Sixteen patients in this group crossed from their assigned therapy, and 128 proceeded to angiography, 13 of whom did not require angioplasty because of patent vessels. Of the remaining 115 patients, only 9 were deemed to have had an unsuccessful rescue-PCI procedure; in 6 of these patients the artery was deemed not amenable to PCI, in one instance affecting 1 patient there was a technical failure of x-ray equipment, and in 2 patients the attempts to open the artery were unsuccessful.

Rescue PCI was commenced (i.e., the wire crossed the lesion) a median of 414 minutes after the onset of pain (interquartile range, 350 to 505). Stents were deployed in 68.5 percent of patients, and a glycoprotein IIb/IIIa receptor inhibitor (abciximab) was administered in 43.4 percent. For patients assigned to rescue PCI rather than re-

\begin{tabular}{|c|c|c|c|c|}
\hline \multirow[t]{2}{*}{ End Point } & \multicolumn{3}{|c|}{ Treatment } & \multirow[t]{2}{*}{ Overall P Value } \\
\hline & $\begin{array}{l}\text { Repeated } \\
\text { Thrombolysis } \\
(\mathrm{N}=142)\end{array}$ & $\begin{array}{c}\text { Conservative } \\
\text { Therapy } \\
(\mathrm{N}=141)\end{array}$ & $\begin{array}{l}\text { Rescue } \mathrm{PCl} \\
(\mathrm{N}=144)\end{array}$ & \\
\hline \multicolumn{5}{|l|}{$\begin{array}{l}\text { Primary end-point events (predetermined } \\
\text { hierarchical analysis) }\end{array}$} \\
\hline Death from any cause - no. ( $\%$ of patients) & $18(12.7)$ & $18(12.8)$ & $9(6.2)$ & 0.12 \\
\hline $\begin{array}{l}\text { Death from cardiac causes - no. (\% of pa- } \\
\text { tients) }\end{array}$ & $15(10.6)$ & $14(9.9)$ & $8(5.6)$ & 0.26 \\
\hline $\begin{array}{l}\text { Recurrent acute myocardial infarction - } \\
\text { no. (\% of patients) }\end{array}$ & $15(10.6)$ & $12(8.5)$ & $3(2.1)$ & $<0.01$ \\
\hline $\begin{array}{l}\text { Cerebrovascular event - } \\
\text { no. (\% of patients) }\end{array}$ & $1(0.7)$ & $1(0.7)$ & $3(2.1)$ & 0.63 \\
\hline Severe heart failure - no. (\% of patients) & $10(7.0)$ & $11(7.8)$ & $7(4.9)$ & 0.58 \\
\hline $\begin{array}{c}\text { Composite primary end point - } \\
\text { no. (\% of patients) }\end{array}$ & $44(31.0)$ & $42(29.8)$ & $22(15.3)$ & $<0.01$ \\
\hline \multicolumn{5}{|l|}{ Secondary end point } \\
\hline \multicolumn{5}{|l|}{ Bleeding events } \\
\hline $\begin{array}{l}\text { Major bleed - no. of patients } \\
\text { (no. of deaths) }\end{array}$ & $7(5)$ & $5(3)$ & $4(0)$ & 0.65 \\
\hline $\begin{array}{l}\text { Minor bleed - no. of patients (no. sheath- } \\
\quad \text { related) }\end{array}$ & $10(3)$ & $8(0)$ & $33(28)$ & $<0.001$ \\
\hline $\begin{array}{l}\text { Blood loss with no identified site - } \\
\text { no. of patients }\end{array}$ & 34 & 33 & 19 & 0.12 \\
\hline \multicolumn{5}{|l|}{ Revascularization } \\
\hline $\mathrm{PCl}$ or $\mathrm{CABG}-$ no. (\% of patients) & $33(23.2)$ & $29(20.6)$ & $19(13.2)$ & $0.08 \dagger$ \\
\hline
\end{tabular}




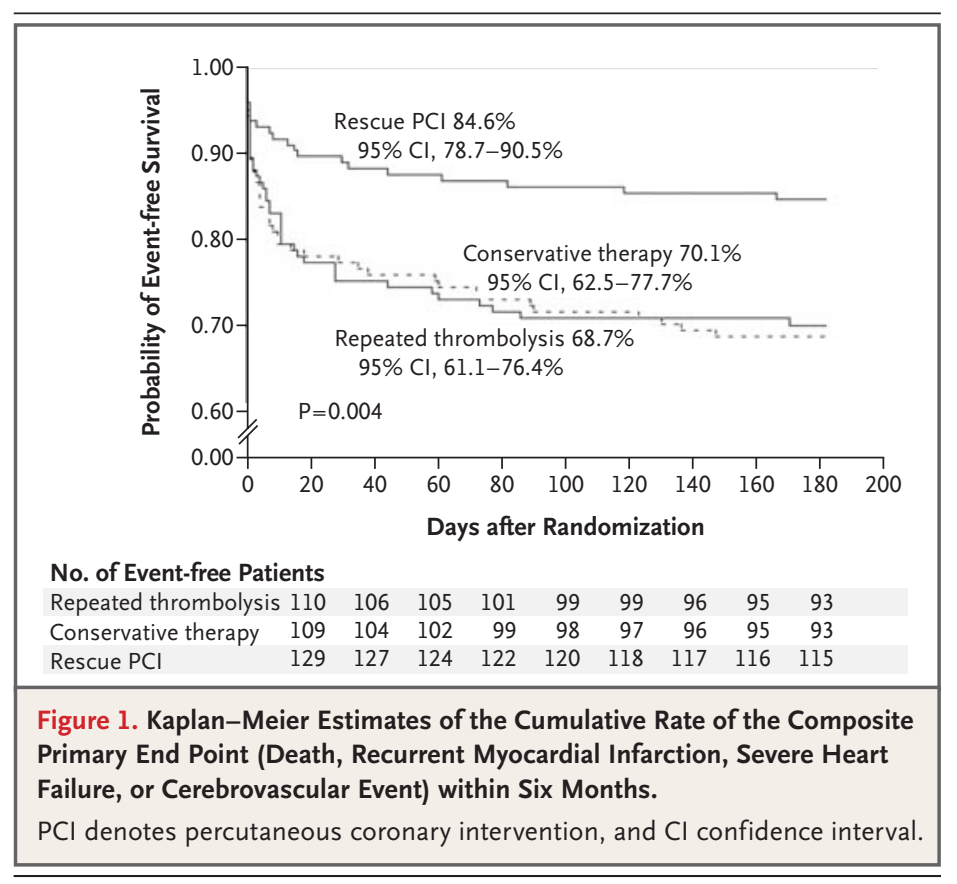

peated thrombolysis, the median additional delay in the time to the assigned treatment was 84 minutes (4.6 hours for rescue PCI vs. 3.2 hours for repeated thrombolysis).

\section{PRIMARY END POINT}

All components of the primary end point were recorded for 406 subjects (95.1 percent). Mortality status was confirmed for the remaining 21 subjects (4.9 percent): 6 each in the repeated-thrombolysis and conservative-therapy groups and 9 in the rescue PCI-group. Data on these subjects were included in the analyses as censored observations, with a median study period of 105 days (range, 5 to 177).

In the rescue-PCI group, 15.3 percent of the patients reached at least one component of the primary end point, as compared with 31.0 percent in the repeated-thrombolysis group and 29.8 percent in the conservative-therapy group (overall $\mathrm{P}=0.003$ ) (Table 3). The rate of event-free survival (Fig. 1) was 84.6 percent in the rescue-PCI group, as compared with 70.1 percent in the conservativetherapy group and 68.7 percent in the repeatedthrombolysis group (overall $\mathrm{P}=0.004$ ). Among patients assigned to rescue PCI, there was no significant difference in event rates between those who were transferred for intervention (16.4 percent) and those who were recruited in hospitals with on-site facilities for intervention (14.6 per- cent, $\mathrm{P}=0.80$ ), and logistic-regression analysis indicated that the time to repeated PCI (up to 12 hours) had no significant effect on outcome. Although the numbers are very small, the incidence of the primary end point was much higher among those who underwent unsuccessful rescue PCI (5 of 9 patients [55.6 percent]) than among those who underwent successful rescue PCI (12 of $106 \mathrm{pa}$ tients [11.3 percent], $\mathrm{P}=0.007$ ).

Age and infarct site were the only baseline characteristics that were identified as predictors of the primary end point by multivariate analysis. Adjusted pairwise hazard ratios (Fig. 2) confirmed a statistically significant benefit of rescue PCI as compared with conservative therapy (hazard ratio, 0.47 ; 95 percent confidence interval, 0.28 to 0.79 ; $\mathrm{P}=0.004$ ) and repeated thrombolysis (hazard ratio, $0.43 ; 95$ percent confidence interval, 0.26 to $0.72 ; \mathrm{P}=0.001$ ). There was no significant difference in benefit between repeated thrombolysis and conservative therapy (hazard ratio, 1.09; 95 percent confidence interval, 0.71 to $1.67 ; \mathrm{P}=0.69$ ).

\section{COMPONENTS OF THE PRIMARY END POINT}

There was a trend toward lower mortality at six months in the rescue-PCI group (6.2 percent) than in either the repeated-thrombolysis group (12.7 percent) or the conservative-therapy group (12.8 percent, $\mathrm{P}=0.12$ for both comparisons) (Table 3). When the rescue-PCI group was compared with the two other groups combined, this difference was statistically significant (hazard ratio, 0.48; 95 percent confidence interval, 0.23 to $0.99 ; \mathrm{P}<0.05$ ). Multivariate analysis identified age and diabetes as significant predictors of death, and the adjusted hazard ratios significantly favored rescue PCI: the hazard ratio for rescue PCI as compared with repeated thrombolysis was 0.42 ( 95 percent confidence interval, 0.19 to $0.94 ; \mathrm{P}<0.04$ ), and the hazard ratio for rescue PCI as compared with conservative therapy was 0.42 (95 percent confidence interval, 0.19 to $0.94 ; \mathrm{P}<0.04)$. The trial was not powered to detect a difference in mortality alone.

There were no significant differences in the rates of cerebrovascular events or severe heart failure among the three treatment groups (Table 3). However, the rate of recurrent myocardial infarction was significantly lower in the rescue-PCI group (2.1 percent) than in the repeated-thrombolysis group (10.6 percent) or the conservativetherapy group (8.5 percent); the hazard ratio for rescue PCI as compared with repeated thromboly- 
sis was 0.23 (95 percent confidence interval, 0.09 to $0.62 ; \mathrm{P}=0.004)$, and the hazard ratio for rescue PCI as compared with conservative therapy was 0.33 (95 percent confidence interval, 0.12 to 0.93 ; $\mathrm{P}=0.04)$.

\section{BLEEDING COMPLICATIONS}

Bleeding events were defined according to a modified TIMI classification (Table 1). ${ }^{17}$ There were no significant differences among the groups in major bleeding events (Table 3). However, there was a tendency toward higher mortality from major bleeding episodes in the repeated-thrombolysis group (four deaths from hemopericardium and one death from intracranial hemorrhage) and the conservative-therapy group (one death from hemothorax and two deaths from intracranial hemorrhage) than in the rescue-PCI group, in which there were no deaths associated with bleeding events. Minor bleeding episodes were significantly more frequent in the rescue-PCI group $(\mathrm{P}<0.001)$; minor bleeding occurred at the access site in 28 patients, 5 of whom required blood transfusion. Among the patients in the rescue-PCI group who had bleeding events, 69 percent had received abciximab, as compared with 43 percent of all patients in this group $(\mathrm{P}=0.17)$. There were no significant differences among the groups in the incidence of bleeding episodes characterized by a fall in hemoglobin without an identified bleeding site.

\section{REVASCULARIZATION}

Revascularization rates tended to be lower in the rescue-PCI group (Table 3). At six months, 86.2 percent of the patients in the rescue-PCI group were free from revascularization, as compared with 77.6 percent of those undergoing conservative therapy and 74.4 percent of those undergoing repeated thrombolysis (overall $\mathrm{P}=0.05$ by the logrank test). The unadjusted hazard ratio for revascularization was 0.50 (95 percent confidence interval, 0.29 to $0.88 ; \mathrm{P}<0.02$ ) for rescue $\mathrm{PCI}$ as compared with repeated thrombolysis and 0.58 (95 percent confidence interval, 0.33 to 1.04 ; $\mathrm{P}<0.07$ ) for rescue PCI as compared with conservative therapy. There was no difference between the two groups not assigned to rescue PCI (hazard ratio for repeated thrombolysis as compared with conservative therapy, 1.17; 95 percent confidence interval, 0.71 to $1.92 ; \mathrm{P}=0.56$ ).

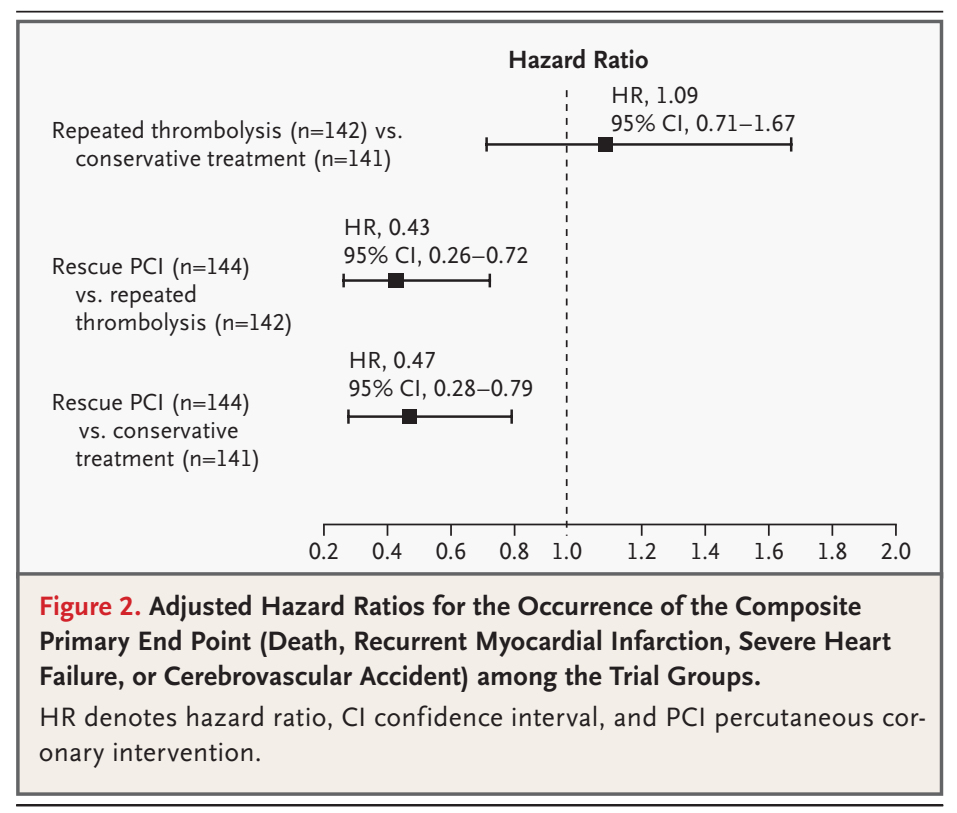

\section{I SCUSSION}

Our study compared three therapeutic options after failed thrombolytic therapy. We found that rescue PCI was superior to either conservative care or repeated thrombolysis, even though a substantial proportion of patients treated with rescue PCI were transferred from hospitals without interventional facilities, and there was a median additional time delay of 84 minutes until treatment with rescue PCI in comparison with repeated thrombolysis. A trend toward a higher frequency of fatal bleeding was noted in both the conservative-treatment group and the repeated-thrombolysis group, but given the small number of cases reported, no firm conclusions can be drawn from these data. The higher rates of nonfatal bleeding in the rescue-PCI group may be due to the use of glycoprotein IIb/IIIa receptor inhibitors.

Previous evidence supporting the use of rescue PCI is limited, and current guidelines recommend it only for certain high-risk subgroups of patients. ${ }^{18,19}$ Rescue PCI has been reported to lower the rate of recurrent myocardial infarction, reduce the incidence of early severe heart failure, and improve one-year survival. ${ }^{12,15}$ However, the sample sizes in most studies have been small; moreover, failed rescue PCI has been associated with a high incidence of adverse outcomes (approximately 30 percent), ${ }^{14,20}$ a result that could 
reduce the overall benefit of the technique..$^{21,22}$ The recent use of stents and glycoprotein IIb/IIIa receptor inhibitors may have improved outcomes in comparison with those in studies performed in the mid-1990s.

The findings of our study favoring the use of rescue PCI contradict those of the recent Middlesbrough Early Vascularization to Limit Infarction (MERLIN) trial, ${ }^{23}$ which found a significant reduction in revascularization rates only. There are a number of important differences between the two trials. The MERLIN trial was a locally confined study, whereas ours was a national multicenter trial. In the MERLIN trial, the first thrombolytic agent was more often streptokinase $(96$ percent, vs. 59 percent in our trial), and eligibility was determined on the basis of electrocardiography at 60 minutes, rather than 90 . This strategy may have reduced the rates of the end points in the conservative-treatment group, since some patients treated with streptokinase probably underwent perfusion at 60 to 90 minutes (as suggested by the fact that 40 percent of the patients in the rescue-PCI group had TIMI grade 3 flow according to angiography before intervention). The MERLIN trial also showed lower rates of stenting and of glycoprotein IIb/IIIa inhibitor use, which may have contributed to a higher reinfarction rate in the rescue-PCI group. For reasons that remain unexplained, the mortality in the rescuePCI group was unusually high in the MERLIN trial, ${ }^{20}$ as was the rate of cerebrovascular events in this group (4.6 percent). In addition, despite the absence of a group randomly assigned to repeated thrombolytic treatment, 11.7 percent of the conservatively treated patients in the MERLIN trial underwent repeated thrombolysis, further confounding the results.

The optimal approach for detecting the failure of thrombolytic therapy has been the subject of much debate..$^{24,25}$ Historically, entry into studies of rescue PCI has been determined by angiographic findings, ${ }^{13,26}$ whereas in clinical practice, failure of reperfusion is generally detected by clinical, noninvasive markers. There is evidence that the ratios of biochemical markers (including creatine kinase $\mathrm{MB}$ fraction, troponin, and myoglobin mass) measured before and 60 minutes after the administration of thrombolytic therapy have good predictive value, ${ }^{27,28}$ with low ratios correlating with poor patency. However, differential degrees of ST-segment resolution also correlate well with TIMI flow grade ${ }^{29-31}$ and predict longer-term outcome. ${ }^{32}$ The value of ongoing pain as a sensitive marker of nonreperfusion is questionable, given its low specificity ${ }^{33}$ and the routine use of analgesia. Although certain markers (e.g., myoglobin) may be considered the most sensitive for detecting failed thrombolytic therapy, these were not widely available in the clinical setting when our trial was designed. Therefore, an ST-segment resolution of 50 percent was considered the most reliable possible entry criterion, and this cutoff was deemed likely to pick up most reperfusion failures, with a low rate of false positives for patent arteries. ${ }^{30,32,34}$

Although the trial was terminated early, termination occurred before the investigators were unblinded to the data and was necessary, given the falling recruitment rates and the finite funding period for the study. In the absence of a full registry, we cannot exclude some element of selection bias in the population enrolled. However, all consecutive patients at each site in whom thrombolytic therapy had failed were evaluated, and the baseline characteristics as recorded in the screening log until November 2002 do not suggest such bias. The great majority of patients, according to this record, were excluded for predefined clinical reasons, with only 4.2 percent being excluded by choice of the patient's physician.

In conclusion, the trial found that rescue PCI after failed thrombolytic treatment was associated with a statistically significant reduction in the incidence of major adverse cardiac and cerebrovascular events, as compared with either repeated thrombolysis or conservative management. These results indicate that rescue PCI, with transfer to a tertiary site if required, should be considered for patients in whom thrombolysis for myocardial infarction with ST-segment elevation fails to achieve reperfusion.

Dr. Gershlick reports having served as a consultant to and received lecture fees from Cordis, Boston Scientific, and Medtronic and being currently in receipt of research grant support from Medtronic; Dr. Baumbach, having served as a consultant to Boston Scientific; Dr. Schofield, having served as a consultant to Cordis and Guidant; and Dr. Dawkins, having served as a consultant to Eli Lilly, Boston Scientific, Guidant, and Conor Medsystems, having received lecture fees from Eli Lilly, Boston Scientific, and Guidant, and having appeared as an expert witness for Boston Scientific. No other potential conflict of interest relevant to this article was reported.

We are indebted to Leslie Shortt for data entry, and to the nursing and medical staff of the cardiac care units and catheter laboratories at all sites. 
APPENDIX

The members of the REACT trial were as follows: Steering Committee - A.H. Gershlick (principal investigator), M. de Belder, H. Swanton, R. Wilcox, K. Abrams, D. de Bono (deceased), and A. Stephens-Lloyd; Data and Safety Committee - K. Fox, J. Birkhead, and M. Bland; End-Point Committee - J. Hampton and S. Davies; Trial coordinators - A. Stephens-Lloyd and S. Hughes; Statisticians - S. Stevens, K. Abrams, and A. Skene; Economic evaluation - M. Buxton and M. Dyer; Investigators, interventionists, and study-site coordinators — Glenfield Hospital, Leicester: J.D. Skehan, J. Kovac, N.J. Samani, and P.J.B. Hubner; Leicester Royal Infirmary, Leicester: I. Squire, L. Shipley, and E. Parker; Leicester General Hospital, Leicester: I. Hudson, R. Pathmanathan, and K. Fairbrother; Royal Infirmary of Edinburgh, Edinburgh: N.G. Uren, D.E. Newby, P. Bloomfield, N.A. Boon, A.D. Flapan, L. Flint, M. O’Donnell, and L. Cameron; Royal Sussex County Hospital, Brighton: A. de Belder, S. Holmberg, D. Hildick-Smith, N. Cooter, and L. Bennett; North Staffordshire Hospital, Stoke-on-Trent: J. Davis, J. Nolan, J. Creamer, D. O'Gorman, J. Machin, and C. Butler; Heartlands Hospital, Birmingham: M. Pitt, P. Ludman, G. Murray, J. Beattie, S. Eccleshall, N. El-Gaylani, J. Pitt, and J. Hulse; Hull Royal Infirmary, Hull: M. Norell, F. Alamgir, J. Caplin, G. Kaye, A. Clark, M. Nasir, J. Bristow, A. Fussey, E. Owen, and A. Baksh; John Raddliffe Hospital, Oxford: A. Banning, N. Alp, H. McCullough, N. Meldrum, C. Hamer, and R. Douthwaite; Bristol Royal Infirmary, Bristol: A. Baumbach, G. Dalton, and K. Carson; Walsgrave Hospital, Coventry: M.F. Shiu, H. Singh, M. Been, P. Glennon, S. Constantinides, and L. Gill; Hairmyres Hospital, East Kilbride: K. Oldroyd, B.D. Vallance, J. Young, and G. Moreland; Papworth Hospital, Cambridge: P. Schofield, M.C. Petch, L.M. Shapiro, S.C. Clarke, H. Millington, A. Emerton, and C. Rhydwen; Southampton General Hospital, Southampton: K. Dawkins, I. Simpson, H. Gray, A. Calver, J. Morgan, Z. Nicholas, and S. Kitt; Addenbrookes Hospital, Cambridge: P. Weissberg, S. Blackwood; Nottingham City Hospital, Nottingham: R. Henderson, D. Falcon-Lang, and M. Marriott; University Hospital of Wales, Cardiff: W. Penny and L. Davies; Royal Devon and Exeter Hospital, Exeter: B. Smith, M. Gandhi, J. Dean, C. Rinaldi, A. Renouf, D. Taylor, and J. Hunt; Royal Surrey County Hospital, Guildford: E. Leatham, R. Mitra, S. Green, and M. Eaton; Wishaw General Hospital, Wishaw, Larnarkshire: M. Malekian and A. Sloey; Derby Royal Infirmary, Derby: M. Millar-Craig and A. Joy; St. Thomas' Hospital, London: S. Redwood, S. Patel, and S. Hogun; Epsom General Hospital, Epsom: S. Odemuyiwa, A. Redwood, and C. Cooper; Southmead Hospital, Bristol: P. Walker, K. Potts, and D. Foster-Hargreaves; West Suffolk Hospital, Bury-St-Edmunds: E. Lee and S. Reader; Western Infirmary, Glasgow: K. Oldroyd, S. Robb, W. Hillis, and J. Kelly; Crosshouse Hospital, Kilmarnock: D. O’Neill and O. El-Wassief; Manchester Heart Centre, Manchester: N. Curzen, F. Fath-Ordoubadi, L. Neyses, and H. Iles-Smith; Royal Alexandra Hospital, Paisley: S. Hood, I. Findlay, and J. Dougall; Hemel Hempstead General Hospital, Hemel Hempstead: D. Hackett and L. Birkhead; Kent and Sussex Hospital, Tunbridge Wells: C. Lawson and J. Highland; Middlesex Hospital, London: H. Swanton and E. Firmin; St. Mary's Hospital, London: R. Foale, J. Mayet, S. Smart, and J. Varghese.

\section{REFERENCES}

1. The GUSTO Angiographic Investigators. The effects of tissue plasminogen activator, streptokinase, or both on coronaryartery patency, ventricular function, and survival after acute myocardial infarction. N Engl J Med 1993;329:1615-22. [Erratum, N Engl J Med 1994;330:516.]

2. Puma JA, Sketch MH Jr, Thompson TD, et al. Support for the open-artery hypothesis in survivors of acute myocardial infarction: analysis of 11,228 patients treated with thrombolytic therapy. Am J Cardiol 1999;83:482-7.

3. Fath-Ordoubadi F, Huehns TY, AlMohammad A, Beatt KJ. Significance of the Thrombolysis in Myocardial Infarc tion scoring system in assessing infarctrelated artery reperfusion and mortality rates after acute myocardial infarction. Am Heart J 1997;134:62-8.

4. French $\mathrm{JK}$, Hyde TA, Patel $\mathrm{H}$, et al Survival 12 years after randomization to streptokinase: the influence of thrombolysis in myocardial infarction flow at three to four weeks. J Am Coll Cardiol 1999; 34:62-9.

5. Budaj A, Brieger D, Steg PG, et al. Global patterns of use of antithrombotic and antiplatelet therapies in patients with acute coronary syndromes: insights from the Global Registry of Acute Coronary Events (GRACE). Am Heart J 2003;146:9991006.

6. Keeley EC, Boura JA, Grines CL. Pri mary angioplasty versus intravenous thrombolytic therapy for acute myocardial infarction: a quantitative review of 23 randomised trials. Lancet 2003;361:13-20.
7. Eagle KA, Goodman SG, Avezum A Budaj A, Sullivan CM, Lopez-Sendon J. Practice variation and missed opportunities for reperfusion in ST-segment-elevation myocardial infarction: findings from the Global Registry of Acute Coronary Events (GRACE). Lancet 2002;359:373-7.

8. The Fibrinolytic Therapy Trialists' (FTT) Collaborative Group. Indications for fibrinolytic therapy in suspected acute myo cardial infarction: collaborative overview of early mortality and major morbidity results from all randomised trials of more than 1000 patients. Lancet 1994;343:31122. [Erratum, Lancet 1994;343:742.] 9. Cannon $\mathrm{CP}$, Gibson $\mathrm{CM}$, McCabe $\mathrm{CH}$, et al. TNK-tissue plasminogen activato compared with front-loaded alteplase in acute myocardial infarction: results of the TIMI 10B trial. Circulation 1998;98:280514.

10. Prendergast BD, Shandall A, Buchal ter MB. What do we do when thromboly sis fails? A United Kingdom survey. Int J Cardiol 1997;61:39-42.

11. Sarullo FM, Americo L, Di Pasquale P, Castello A, Mauri F. Efficacy of rescue thrombolysis in patients with acute myocardial infarction: preliminary findings. Cardiovasc Drugs Ther 2000;14:83-9.

12. Ellis SG, da Silva ER, Heyndrickx G, et al. Randomized comparison of rescue angioplasty with conservative management of patients with early failure of throm bolysis for acute anterior myocardial in farction. Circulation 1994;90:2280-4 13. Ross AM, Lundergan CF, Rohrbeck $\mathrm{SC}$, et al. Rescue angioplasty after failed thrombolysis: technical and clinical outcomes in a large thrombolysis trial. J Am Coll Cardiol 1998;31:1511-7.

14. Sutton AG, Campbell PG, Grech ED, et al. Failure of thrombolysis: experience with a policy of early angiography and rescue angioplasty for electrocardiographic evidence of failed thrombolysis. Heart 2000;84:197-204.

15. Ellis SG, Da Silva ER, Spaulding CM, Nobuyoshi M, Weiner B, Talley JD. Review of immediate angioplasty after fibrinolytic therapy for acute myocardial infarction: insights from the RESCUE I, RESCUE II, and other contemporary clinical experiences. Am Heart J 2000;139:1046-53.

16. Parmar MKB, Machin D. Survival analysis: a practical approach. Chichester, England: John Wiley, 1995.

17. Bovill EG, Tracy RP, Knatterud GL, et al. Hemorrhagic events during therapy with recombinant tissue plasminogen activator, heparin, and aspirin for unstable angina (Thrombolysis in Myocardial Ischemia, phase IIIB trial). Am J Cardiol 1997;79:391-6.

18. Antman EM, Anbe DT, Armstrong PW, et al. ACC/AHA guidelines for the management of patients with ST-elevation myocardial infarction: a report of the American College of Cardiology/American Heart Association Task Force on Practice Guidelines (Committee to Revise the 1999 Guidelines for the Management of Patients with Acute Myocardial Infarction). J Am Coll Cardiol 2004;44:E1-E211.

19. Van de Werf F, Ardissino D, Betriu A, et al. Management of acute myocardial 
infarction in patients presenting with STsegment elevation: The Task Force on the Management of Acute Myocardial Infarction of the European Society of Cardiology. Eur Heart J 2003;24:28-66.

20. Bar FW, Ophnis TJ, Frederiks J, et al. Rescue PTCA following failed thromboly sis and primary PTCA: a retrospective study of angiographic and clinical outcome. J Thromb Thrombolysis 1997;4:281-8.

21. Gibson CM, Cannon CP, Greene RM, et al. Rescue angioplasty in the Thrombolysis in Myocardial Infarction (TIMI) trial. Am J Cardiol 1997;80:21-6.

22. McKendall GR, Forman S, Sopko G, Braunwald E, Williams DO. Value of rescue percutaneous transluminal coronar angioplasty following unsuccessful thrombolytic therapy in patients with acute myocardial infarction. Am J Cardiol 1995;76 1108-11.

23. Sutton AG, Campbell PG, Graham R, et al. A randomized trial of rescue angioplasty versus a conservative approach fo failed fibrinolysis in ST-segment elevation myocardial infarction: the Middlesbrough Early Revascularization to Limit INfarction (MERLIN) trial. J Am Coll Cardiol 2004; 44:287-96.

24. de Lemos JA, Morrow DA, Gibson CM et al. Early noninvasive detection of failed epicardial reperfusion after fibrinolytic therapy. Am J Cardiol 2001;88:353-8.
25. Lavin F, Kane M, Forde A, Gannon F, Daly K. Comparison of five cardiac markers in the detection of reperfusion after thrombolysis in acute myocardial infarction. Br Heart J 1995;73:422-7.

26. el Deeb F, Ciampricotti R, el Gamal M, Michels R, Bonnier H, Van Gelder B. Value of immediate angioplasty after intravenous streptokinase in acute myocardial infarction. Am Heart J 1990;119:786 91.

27. Stewart JT, French JK, Theroux P, et al Early noninvasive identification of failed reperfusion after intravenous thrombolytic therapy in acute myocardial infarction. J Am Coll Cardiol 1998;31:1499-505.

28. Tanasijevic MJ, Cannon CP, Antman $\mathrm{EM}$, et al. Myoglobin, creatine-kinase-MB and cardiac troponin-I 60-minute ratios predict infarct-related artery patency afte thrombolysis for acute myocardial infarction: results from the Thrombolysis in Myocardial Infarction study (TIMI) 10B. J Am Coll Cardiol 1999;34:739-47.

29. Fernandez AR, Sequeira RF, Chakko $S$, et al. ST segment tracking for rapid determination of patency of the infarct-related artery in acute myocardial infarction. J Am Coll Cardiol 1995;26:675-83.

30. Zeymer U, Schroder R, Tebbe U, Molhoek GP, Wegscheider K, Neuhaus KL. Non-invasive detection of early infarct vessel patency by resolution of ST-segment el- evation in patients with thrombolysis for acute myocardial infarction: results of the angiographic substudy of the Hirudin for Improvement of Thrombolysis (HIT)-4 trial. Eur Heart J 2001;22:769-75.

31. Gibson CM, Karha J, Giugliano RP, et al. Association of the timing of ST-segment resolution with TIMI myocardial perfusion grade in acute myocardial infarction. Am Heart J 2004;147:847-52.

32. Schroder R, Wegscheider K, Schroder K, Dissmann R, Meyer-Sabellek W. Extent of early ST segment elevation resolution: a strong predictor of outcome in patients with acute myocardial infarction and a sensitive measure to compare thrombolytic regimens: a substudy of the International Joint Efficacy Comparison of Thrombolytics (INJECT) trial. J Am Coll Cardiol 1995; 26:1657-64.

33. Christenson RH, Ohman EM, Topol EJ, et al. Assessment of coronary reperfusion after thrombolysis with a model combining myoglobin, creatine kinase-MB, and clinical variables. Circulation 1997;96: 1776-82.

34. Andrews J, Straznicky IT, French JK, et al. ST-segment recovery adds to the assessment of TIMI 2 and 3 flow in predicting infarct wall motion after thrombolytic therapy. Circulation 2000;101:2138-43.

Copyright $\odot 2005$ Massachusetts Medical Society. of Medical Journal Editors plan to consider clinical trials for publication only if they have been registered (see N Engl J Med 2004;351:1250-1).

The National Library of Medicine's www.clinicaltrials.gov is a free registry, open to all investigators, that meets the committee's requirements. 